\title{
Myristic acid is associated to low plasma HDL cholesterol levels in a Mediterranean population and increases HDL catabolism by enhancing HDL particles trapping to cell surface proteoglycans in a liver hepatoma cell model
}

\author{
Davide Noto ${ }^{1}$, Francesca Fayer ${ }^{1}$, Angelo B. Cefalù, Ida Altieri, Ornella Palesano, \\ Rossella Spina, Vincenza Valenti, Maria Pitrone, Giuseppe Pizzolanti, Carlo M. Barbagallo, \\ Carla Giordano, Maurizio R. Averna* \\ Department of Biomedicine, Internal Medicine and Medical Specialties (DIBIMIS), University of Palermo, Palermo, Italy
}

\section{A R T I C L E I N F O}

\section{Article history:}

Received 27 August 2015

Received in revised form

3 December 2015

Accepted 23 December 2015

Available online 28 December 2015

\section{Keywords:}

Fatty acids

Population study

HDL cholesterol levels

HepG2 cells

\begin{abstract}
A B S T R A C T
Background: HDL-C plasma levels are modulated by dietary fatty acid (FA), but studies investigating dietary supplementation in FA gave contrasting results. Saturated FA increased HDL-C levels only in some studies. Mono-unsaturated FA exerted a slight effect while poly-unsaturated FA mostly increased plasma HDL-C.

Aims: This study presents two aims: i) to investigate the relationship between HDL-C levels and plasma FA composition in a Sicilian population following a "Mediterranean diet", ii) to investigate if FA that resulted correlated with plasma HDL-C levels in the population study and/or very abundant in the plasma were able to affect HDL catabolism in an "in vitro" model of cultured hepatoma cells (HepG2). Results: plasma HDL-C levels in the population correlated negatively with myristic acid (C14:0, $\beta=-0.24, p<0.01)$, oleic acid (C18:1n9, $\beta=-0.22, p<0.01)$ and cis-11-Eicosenoic (C20:1n9, $\beta=-0.19$, $\mathrm{p}=0.01)$ and positively with palmitoleic acid $(\mathrm{C} 16: 1, \beta=+0.19, \mathrm{p}=0.03)$. HepG2 cells were conditioned with FA before evaluating HDL binding kinetics, and only C14:0 increased HDL binding by a nonsaturable pathway. After removal of heparan sulphate proteoglycans (HSPG) by heparinases HDL binding dropped by $29 \%$ only in C14:0 conditioned cells $(\mathrm{p}<0.05)$. C14:0 showed also the highest internalization of HDL-derived cholesteryl esters ( $C E,+32 \% \mathrm{p}=0.01$ vs. non-conditioned cells).

Conclusions: C14:0 was correlated with decreased plasma HDL-C levels in a Mediterranean population. C14:0 might reduce HDL-C levels by increasing HDL trapping to cell surface HSPG and CE stripping from bound HDL. Other mechanisms are to be investigated to explain the effects of other FA on HDL metabolism.
\end{abstract}

๑) 2015 Elsevier Ireland Ltd. All rights reserved.

\section{Introduction}

Dietary supplementation of unsaturated fatty acids (FA) protects against atherosclerosis and cardiovascular (CV) events [1]. The effects of dietary FA on the lipid metabolism have been widely investigated: mono- and poly-unsaturated FA (MUFA/PUFA)

\footnotetext{
* Corresponding author. Department of Internal Medicine, Policlinico "Paolo Giaccone", Via del Vespro, 141 I-90127 Palermo, Italy.

E-mail address: avernam@mbox.unipa.it (M.R. Averna).

1 Department of Internal Medicine, Policlinico "Paolo Giaccone", Via del Vespro, 141 I-90127 Palermo, Italy.
}

supplemented to the diet were effective in lowering total cholesterol (TC) and LDL cholesterol (LDL-C), while saturated FA (SFA) increased TC and LDL-C [2,3]. HDL cholesterol (HDL-C) showed a slight decrease with PUFA dietary supplementation [3] or a slight increase with any FA in other studies [2]. Plasma levels of PUFA, but not SFA, were associated with lower apolipoprotein $\mathrm{AI}$ (apo-AI) and HDL-C levels in the Framingham study, but with different features in men and women [4]. Animal models showed inconsistent results. PUFA and MUFA were both effective in decreasing the TC and LDL-C levels compared to SFA in some models, but HDL-C levels were decreased mainly by PUFA $[5,6]$.

The control of HDL-C plasma levels involves different pathways 
[7]: i) synthesis of the HDL-constitutive apolipoproteins, such as apoAI and apoAII, and lipidation of the nascent lipoproteins by specific lipid transporters (as ATP-binding cassette, sub-family A member 1, ABCA1 and scavenger receptor class I type B1, SRB1), ii) remodeling of circulating HDLs by plasma enzymatic activities as lipoprotein lipase (LPL), hepatic lipase (HL) endothelial lipase (EL), lecithin cholesterol transfer protein (LCAT) and/or lipid transport proteins, as cholesteryl ester transfer protein (CETP), and phospholipids transfer protein (PLTP), iii) clearance from the circulation via specific cell membrane receptors, such as the SR-B1. There are evidences suggesting that plasma non-esterified FA (NEFA) control several key steps of HDL metabolism. Unsaturated NEFA downregulate $A B C A 1$ and $A B C G 1$ genes expressions [8]. NEFA also modulate LPL [9], CETP [10] and HL [11]. The control of the lipid metabolism by NEFA is mediated by the modulation of the Peroxisome Proliferator-Activated Receptors (PPARs) activities [12]. The hepatic HDL receptor, SR-B1, appears to be under the control of PPAR gamma-RXR heterodimer [13], nevertheless studies evaluating the regulation of SR-B1 expression gave contrasting results. Unsaturated FA in macrophages and liver cells did not alter SR-B1 expression [8] while rats fed with PUFA increased it [14].

The first aim of this paper was to evaluate the relationship between plasma NEFA composition and HDL-C levels in a population of Southern Italy from the "Ventimiglia Hearth Study", an epidemiological project started in 1989 with the aims to survey a typical rural Mediterranean population in search of CV risk factors and to register CV events over the years of follow up $[15,16]$. In the second part of the study the NEFA significantly correlated with plasma HDL-C levels in this population were investigated "in vitro" for their ability to modify HDL catabolism using cultured liver hepatoma cells (HepG2). HDL binding and/or internalization into liver cells were investigated after conditioning them with different synthetic FAs. Data concerning the effect of different FAs on SR-B1 expression and the heparan sulphate proteoglycans (HSPG) contribution to "in vitro" HDL catabolism are also presented.

\section{Methods}

\subsection{Study subjects}

The subjects of the present study were selected from the database of the Epidemiological project "Ventimiglia di Sicilia Heart Study" [15,16]. About nine hundreds sera were stored in 2002-2003 for epidemiologic analyses and were analyzed within a year from storage. In the present study, a subset of the sampled population was selected using a block randomization procedure in order to represent the original population in terms of age, gender, BMI and type 2 diabetes mellitus distribution. Randomization was performed with a 1:5 ratio, so that about two hundreds subjects were selected for subsequent analyses.

The adopted procedures were in accordance with the Helsinki Declaration of 1975, as revised in 1983 and were approved by the Ethical Committee of the University of Palermo. All the subjects gave their informed consent to participate to the study.

\subsection{Laboratory analyses}

Lipid profile, blood glucose and other relevant biochemical parameters were measured using standard enzymatic-colorimetric procedures (Roche Diagnostics, Basel Switzerland) on a COBAS MIRA plus auto-analyzer (Roche Diagnostics, Basel Switzerland). LDL-C was calculated by the Friedewald formula. Detailed procedures of the epidemiological study methodologies are described elsewhere [15,16].

NEFA were measured in the plasma by Gas Chromatography-
Mass Spectrometry (GC/MS). NEFA were extracted from the plasma adapting the method described by Lepage and Roy [17]. Plasma aliquots used for NEFA determination were stored after addition of a mixture of an anti-proteases cocktail (Roche Diagnostic, Basel Switzerland) and $50 \mu \mathrm{M}$ beta-hydroxy-toluene and analyzed within a year from storage. Random samples were occasionally retested to check for consistency of NEFA determination after prolonged storage. Twenty five $\mu \mathrm{L}$ of plasma were used, since the recovery of NEFA was linear up to $50 \mu \mathrm{L}$ of plasma (data not shown). The extraction procedure was checked for possible release of fatty acids from triglycerides by spiking $5 \mu \mathrm{L}$ of Glyceryl Tri(hexadecanoate-1-13C), (Sigma Aldrich, MO, U.S.A.) in some samples. The amount of $1-13 \mathrm{C}$ hexadecanoate (C16:0, palmitate) released during the extraction procedure was negligible (data not shown). Extracted NEFA were converted to methyl ester (FAME) and injected in a Hewlett Packard (Palo Alto, CA, U.S.A.) 5960 Gas chromatograph equipped with a $100 \mathrm{~m} \times 0.25 \mathrm{~mm}$ SP2560 column (Supelco, Bellefonte, U.S.A.) and coupled to a Hewlett Packard 5973 inert Mass spectrometer. GC/MS conditions were: injection split to a 1:30 ratio, injector temperature $180^{\circ} \mathrm{C}$. The oven initial temperature was $80^{\circ} \mathrm{C}$ for $4 \mathrm{~min}$, and then it increased to $220^{\circ} \mathrm{C}$ at $8{ }^{\circ} \mathrm{C} /$ min and remained at $220^{\circ} \mathrm{C}$ for $32 \mathrm{~min}$. All reagents and standards were purchased from Sigma-Aldrich (Sigma-Aldrich, MO, U.S.A.).

MS was used in Single ion monitoring (SIM mode). Eleven $\mathrm{m} / \mathrm{z}$ characteristic of saturated, mono-di- tri-tetra-enoic or n-enoic fatty acids were selected as described in the "AOCS lipid library" site according to Christie W. et al. (http://lipidlibrary.aocs.org/ms/ masspec.html).

Calibration curves were obtained by using true fatty acids standards (FAME, Supelco, Sigma-Aldrich), heptadecanoic acid (C17:0) was used as internal standard (Sigma-Aldrich). All calibration curves were highly linear between 0 and $20 \mu \mathrm{g}$ of injected FAME, (all Pearson's R's were $>0.996$, data not shown); all calibration points were prepared in triplicate spiking normal plasma with scalar amount of standards and the curves was accepted if the coefficients of variation for the repeated measures were below $5 \%$ (data not shown).

\subsection{Lipoproteins isolation and fluorescent labeling}

Normal lipoproteins were isolated from a large pool obtained by young healthy blood donors. Plasma was aliquoted and stored after the addition of the anti-proteases and anti-oxidant cocktail described before. Plasma HDL fractions were obtained by sequential ultracentrifugation in the $1.063-1.210 \mathrm{~g} / \mathrm{mL}$ density range in a L90 K Optima Beckman-Coulter Ultracentrifuge (Beckman Coulter, Fullerton, CA, U.S.A.). HDL particles were labeled with DIL (dioctadecyl-indo-carbocyanine iodide) as described elsewhere [18]. In order to label HDL CE, recombinant HDLs containing BODIPY FL12 (a fluorescent analog of cholesteryl esters (CE) from Molecular Probes-Life Technologies, Eugene, (OR) U.S.A.) were prepared as described elsewhere [19]. The BODIPY FL12 molecule is actively hydrolyzed within lysosomes, but not by cholesteryl esterase.

\subsection{Cell cultures and FA conditioning}

HepG2 hepatoma cells were grown at $37{ }^{\circ} \mathrm{C}, 5 \% \mathrm{CO}_{2}$, in Dulbecco's modified Eagle's medium (DMEM glutamax, Gibco BRL, Gaithersburg, Maryland, United States) supplemented with $10 \%$ Fetal Bovine Serum, $100 \mathrm{U} / \mathrm{mL}$ penicillin and $100 \mu \mathrm{g} / \mathrm{mL}$ streptomycin (Gibco BRL), 1\% non essential amino acids. Cells were grown to sub-confluence and seeded in 6 or 24 wells plates (Corning Life Sciences, MA, U.S.A.) as specified. In conditioning experiments FA were first complexed to Bovine Serum Albumin (BSA, Sigma-Aldrich, St. Louis, MO, U.S.A.) mixing a solution of $100 \mathrm{mM}$ FA in 
0.1 $\mathrm{M} \mathrm{NaOH}$ with a $10 \%$ FA-free BSA solution prepared in $\mathrm{H}_{2} \mathrm{O}$, at $55{ }^{\circ} \mathrm{C}$ for $15 \mathrm{~min}$. The complexed FA were supplemented in the medium to achieve $0.5 \mathrm{mM}$ in $1 \% \mathrm{BSA}$, or $0.25 \mathrm{mM}$ when indicated. Non-conditioned cells were supplemented with BSA alone. Five fatty acids were used in all experiments: myristic acid (C14:0), palmitoleic acid (C16:1), stearic acid (C18:0), oleic acid (C18:1n9), linoleic acid (C18:2n6), all from Sigma-Aldrich.

\subsection{Fluorescent HDL binding to cells surface in HepG2 hepatoma cells}

HepG 2 cells were seeded in 24 wells plates $\left(5 \times 10^{4}\right.$ cells $\times$ well $)$ and grown to sub-confluence. Eighteen hours before the experiments, cells were supplemented with different FA at $0.5 \mathrm{mM}$ concentration in 1\% BSA [20]. The assays were performed in triplicate. Cells were incubated for $2 \mathrm{~h}$ with increasing amount of DIL-HDL (from 0 to $120 \mu \mathrm{g} / \mathrm{mL}$ ) at $4{ }^{\circ} \mathrm{C}$ to evaluate HDL binding. At the end of the incubation, wells were washed trice with cold phosphate buffer solution (PBS) plus $2 \mathrm{mM} \mathrm{CaCl}_{2}, 1 \mathrm{mM} \mathrm{MgCl}$, and cells were lysed in $0.1 \mathrm{~N} \mathrm{NaOH}, 1 \%$ sodium dodecyl sulphate (SDS) for $1 \mathrm{~h}$ at $37{ }^{\circ} \mathrm{C}$. Cell lysates aliquots were used for protein commercial determinations (BCA micro, Pierce Biotechnology, U.S.A.). Lysates were cleared by centrifugation at $14.000 \mathrm{rpm}$ in a microfuge at $4{ }^{\circ} \mathrm{C}$ and cell incorporated fluorescence was read on a RXL10 Shimadzu fluorometer equipped with a cell holder (Shimadzu Corporation, Tokyo, Japan) at excitation $535 \mathrm{~nm}$ and emission $570 \mathrm{~nm}$. DIL-HDL binding was calibrated against a DIL-HDL scale in lysis buffer. Results were calculated as ng of incorporated DIL-HDL/mg of cell proteins.

\subsection{Fluorescent HDL binding to cell surface in HepG2 hepatoma cells after heparinases treatment}

To evaluate the role of the HSPG in HDL surface binding to FA conditioned cells, cultures were treated with heparinases to disrupt the cell surface HSPG matrix. The assays were performed in triplicate. Four hours before the HDL binding experiment, Heparinase I and III (Sigma-Aldrich), $4 \mathrm{IU} / \mathrm{mL}$ each, were added to the cells as described elsewhere [21]. A single dose of DIL HDL ( $40 \mu \mathrm{g} / \mathrm{mL})$ was administered to the cells after heparinases treatment according to the protocol described previously.

In the same setting HDL binding was evaluated with and without heparinases treatment, and the result of the treatment was expressed for every FA as percent loss of binding relative to the HDL binding without heparinases treatment.

\subsection{Fluorescent HDL-CE internalization into HepG2 hepatoma cells}

BODIPY FL-12 labeled-HDL were prepared as described above. HepG 2 cells were seeded in 24 wells plates and conditioned with FA as described above. The assays were performed in triplicate. Cells were incubated with $30 \mu \mathrm{g} / \mathrm{mL}$ of fluorescent HDL for $4 \mathrm{~h}$ at $37^{\circ} \mathrm{C}$. After incubation, cells were washed twice with PBS and trypsinized in $0.05 \%$ trypsin, $0.02 \%$ EDTA (Sigma-Aldrich). Trypsin was inactivated by adding culture medium and cells were centrifuged at $1000 \mathrm{~g}$ for $5 \mathrm{~min}$. After two washes with cold PBS plus $2 \mathrm{mM} \mathrm{CaCl}_{2}$, $1 \mathrm{mM} \mathrm{MgCl}$, cells were suspended in PBS and subjected to cell fluorocytometry in a FACSCalibur (BectonDickinson, San Jose, CA, U.S.A.) fluorocytometer using the Fl1 channel. Median fluorescence intensities (MFI), corrected for cells auto-fluorescence, were obtained by CellQuest Pro software (BD) and they were considered as measures of internalized CE. Data of CE internalization were expressed as proportions of non-conditioned (BSA) cells.

\subsection{SR-B1 protein expression on HepG2 hepatoma cells membrane by immuno-cytofluorimetry}

The HepG2 were grown in 6 well plates to sub-confluence and conditioned for $24 \mathrm{~h}$ with FA as described above. The assays were performed in triplicate. After conditioning, cells were washed twice with PBS plus $2 \mathrm{mM} \mathrm{CaCl} 2,1 \mathrm{mM} \mathrm{MgCl}$ and trypsinized in $0.05 \%$ trypsin, 0.02\% EDTA (Trypsin-EDTA solution $1 \times$, Sigma-Aldrich). Trypsin was inactivated by adding cell culture medium and the cells, collected in tubes, were centrifuged at $1000 \mathrm{~g}$ for $5 \mathrm{~min}$. After two washes with PBS, the cells were suspended in 1\% BSA in PBS. The cellular suspensions were incubated overnight at $4{ }^{\circ} \mathrm{C}$ with a 1:50 dilution of rabbit polyclonal anti SR-B1 antibody (donated kindly by Prof. Schonfeld G., Washington University di St. Louis, MO - U.S.A.) in PBS and 1\% BSA followed by a $1 \mathrm{~h}$ incubation with a 1:100 dilution of a Alexa-fluor 488 conjugated secondary antirabbit antibody (Life technologies). After a final wash, Cells were analyzed by the FACSCalibur using the Fl1 channel and analyzed by CellQuest Pro software (BD) as before. Median values of fluorescence intensity (subtracted of cells auto-fluorescence) were considered as measures of surface SR-B1. Data were expressed as proportions of BSA conditioned cells.

\subsection{Statistics}

Differences in clinical and biochemical parameters in the population study were evaluated by Student's T-test. Univariate correlations were evaluated by Pearson's $R$, while independent correlations were evaluated by multiple regression analysis (MRA) after adjustment for confounders (age, gender, BMI), using a stepforward option. A set of step-backward MRA were performed in parallel with similar results (data not shown). Statistics were calculated by the SYSTAT 12 software (SYSTAT corp., CA, U.S.A.).

Kinetics curves of DIL-HDL binding to HepG2 cells were fitted with a Michaelis-Menten (MM) equation model modified by adding a linear component in order to take into account a nonspecific, non-saturable HDL binding pathway (Supplementary Equation (1)). Curve fitting was performed using the nls2 ("Nonlinear regression with brute force") package from the $\mathrm{R}$ statistic software (https://cran.r-project.org/web/packages/nls2/index. html). The software calculated estimates of MM parameters with relative standard errors of estimated: Bmax expressed the amount of DIL-HDL bound to saturable sites on the cell surface, $\mathrm{Km}$ expressed the MM constant, and Kasp expressed the linear nonspecific binding constant (see Supplementary Equation (1)). Differences in the estimated kinetics parameters between nonconditioned cells and FA conditioned cells were evaluated from calculated means and SD by Student's T test.

\section{Results}

\subsection{Relationship between HDL-C levels and plasma FA in a Mediterranean population}

Table 1 shows clinical data and NEFA profile of the study population divided according to gender. The table shows that the only biochemical parameters significantly differing between males ( $\mathrm{n}=103$ ) and females $(\mathrm{n}=97)$ were TC, HDL-C and TG (nearly significant, $\mathrm{p}=0.06$ ), all of them higher in females. TG/HDL-C (mg to $\mathrm{mg}$ ratio) was higher in males. No differences in plasma NEFA proportions were detected with the exception of $c 18: 2 \mathrm{n} 6(\mathrm{p}=0.03)$ and aggregated PUFA ( $\mathrm{p}=0.02)$ slightly higher in females.

Table 2 shows the correlations between HDL-C plasma levels and plasma NEFA relative amounts. At univariate analysis (column $2)$, HDL-C levels were correlated positively with PUFA $(+0.28$, 
Table 1

Clinical and Biochemical parameters in the study sample.

\begin{tabular}{|c|c|c|c|}
\hline Parameter & Males $(n=103)$ & Females $(\mathrm{n}=97)$ & T-test $\mathrm{p}^{\mathrm{a}}$ \\
\hline Age (years) & $55.43 \pm 19.38$ & $54.62 \pm 18.95$ & 0.77 \\
\hline BMI $(\mathrm{kg} / \mathrm{m} 2)$ & $27.96 \pm 5.16$ & $29.37 \pm 6.67$ & 0.10 \\
\hline Waist(cm) & $95.29 \pm 12.27$ & $92.23 \pm 14.86$ & 0.12 \\
\hline Systolic BP (mm/Hg) & $126.73 \pm 21.58$ & $126.19 \pm 21.54$ & 0.86 \\
\hline Diastolic BP (mm/Hg) & $77.56 \pm 10.09$ & $76.36 \pm 9.42$ & 0.40 \\
\hline Total cholesterol (mmol/L) & $4.84 \pm 0.91$ & $5.15 \pm 1$ & 0.02 \\
\hline Triglycerides (mmol/L) & $1.32 \pm 0.75$ & $1.13 \pm 0.57$ & 0.06 \\
\hline HDL cholesterol (mmol/L) & $1.00 \pm 0.3$ & $1.18 \pm 0.3$ & $<0.01$ \\
\hline LDL cholesterol (mmol/L) & $3.21 \pm 0.76$ & $3.4 \pm 0.81$ & 0.10 \\
\hline Fasting blood glucose (mmol/L) & $5.01 \pm 1.29$ & $4.99 \pm 1.11$ & 0.91 \\
\hline $\mathrm{C}$ reactive protein $(\mathrm{mg} / \mathrm{dL})$ & $0.31 \pm 0.33$ & $0.38 \pm 0.71$ & 0.34 \\
\hline TG/HDL-C (mg/mg ratio) & $3.7 \pm 4.21$ & $2.37 \pm 1.39$ & $<0.01$ \\
\hline \multicolumn{4}{|l|}{ plasma NEFA (proportion) } \\
\hline C14:0 (myristic) & $0.009 \pm 0.005$ & $0.008 \pm 0.004$ & 0.2 \\
\hline C16:0 (palmitic) & $0.229 \pm 0.044$ & $0.219 \pm 0.03$ & 0.09 \\
\hline C16:1 (palmitoleic) & $0.015 \pm 0.009$ & $0.015 \pm 0.006$ & 0.83 \\
\hline $\mathrm{C} 18: 0$ (stearic) & $0.09 \pm 0.031$ & $0.085 \pm 0.024$ & 0.26 \\
\hline C18:1n9 (oleic) & $0.208 \pm 0.051$ & $0.197 \pm 0.042$ & 0.10 \\
\hline C18:2n6 (linoleic) & $0.342 \pm 0.104$ & $0.372 \pm 0.081$ & 0.03 \\
\hline C18:3n6 ( $\gamma$-linolenic) & $0.003 \pm 0.001$ & $0.003 \pm 0.001$ & 0.62 \\
\hline C18:3n3 ( $\alpha$-linolenic) & $0.001 \pm 0.001$ & $0.001 \pm 0.001$ & 0.56 \\
\hline C20:1n9 (cis-11-Eicosenoic) & $0.028 \pm 0.018$ & $0.025 \pm 0.011$ & 0.21 \\
\hline C20:2 (cis-11,14-Eicosadienoic) & $0.002 \pm 0.001$ & $0.002 \pm 0.001$ & 0.74 \\
\hline C20:3n6 (cis-8,11,14-Eicosatrienoic) & $0.019 \pm 0.006$ & $0.02 \pm 0.005$ & 0.20 \\
\hline C20:4n6 (Arachidonic) & $0.003 \pm 0.001$ & $0.003 \pm 0.001$ & 0.67 \\
\hline C20:5n3 (cis-5,8,11,14,17-Eicosapentaenoic) & $0.005 \pm 0.003$ & $0.005 \pm 0.003$ & 0.42 \\
\hline C22:6n3 (cis-4,7,10,13,16,19-Docosahexaenoic) & $0.018 \pm 0.008$ & $0.018 \pm 0.007$ & 0.55 \\
\hline \multicolumn{4}{|l|}{ Aggregated NEFA } \\
\hline SFA & $0.32 \pm 0.06$ & $0.31 \pm 0.04$ & 0.07 \\
\hline MUFA & $0.22 \pm 0.05$ & $0.21 \pm 0.04$ & 0.11 \\
\hline PUFA & $0.42 \pm 0.09$ & $0.44 \pm 0.07$ & 0.02 \\
\hline
\end{tabular}

Biochemical parameters and plasma NEFA profiles in the Ventimiglia Heart Study population divided by gender.

a Student's T-test p-values, Males vs. Females.

Table 2

Correlation of plasma fatty acids composition with HDL cholesterol levels.

\begin{tabular}{|c|c|c|}
\hline Plasma NEFA & Pearson's R ( $\mathrm{p}$ value) ${ }^{\mathrm{a}}$ & Std coefficient ( $\mathrm{p}$ value $)^{\mathrm{b}}$ \\
\hline C14:0 (myristic) & $-0.27(<0.01)$ & $-0.24(<0.01)$ \\
\hline $\mathrm{C} 16: 0$ (palmitic) & $-0.17(0.06)$ & \\
\hline C16:1 (palmitoleic) & $-0.09(0.18)$ & $+0.19(0.03)$ \\
\hline C18:0 (stearic) & $-0.08(0.27)$ & \\
\hline C18:1n9 (oleic) & $-0.27(<0.01)$ & $-0.22(<0.01)$ \\
\hline C18:2n6 (linoleic) & $+0.28(<0.01)$ & $\operatorname{Excl}(0.96)$ \\
\hline C18:3n6 ( $\gamma$-linolenic $)$ & $0.01(0.89)$ & \\
\hline C18:3n3 ( $\alpha$-linolenic) & $-0.12(0.12)$ & \\
\hline C20:1n9 (cis-11-Eicosenoic) & $-0.24(<0.01)$ & $-0.19(0.01)$ \\
\hline C20:2 (cis-11,14-Eicosadienoic) & $-0.04(0.58)$ & \\
\hline C20:3n6 (cis-8,11,14-Eicosatrienoic) & $+0.05(0.47)$ & \\
\hline C20:4n6 (Arachidonic) & $+0.10(0.16)$ & \\
\hline C20:5n3 (cis-5,8,11,14,17-Eicosapentaenoic) & $+0.03(0.64)$ & \\
\hline C22:6n3 (cis-4,7,10,13,16,19-Docosahexaenoic) & $-0.01(0.87)$ & \\
\hline \multicolumn{3}{|l|}{ Aggregated NEFA } \\
\hline Saturated NEFA & $-0.17(0.01)$ & $\operatorname{Excl}(0.61)$ \\
\hline Mono-unsaturated NEFA & $-0.27(<0.01)$ & $\operatorname{Excl}(0.68)$ \\
\hline Poly-unsaturated NEFA & $+0.28(<0.01)$ & $\operatorname{Excl}(0.96)$ \\
\hline
\end{tabular}

a Pearson's R Univariate correlation.

b Multiple regression analysis adjusted for age and gender. Statistical p values in brackets.

$\mathrm{p}<0.01)$ mainly because of $\mathrm{C} 18: 2 \mathrm{n} 6$ correlation $(+0.28, \mathrm{p}<0.01)$ and negatively with MUFA $(-0.27, \mathrm{p}<0.01)$ mainly because of C18:1n9 $(-0.27, \mathrm{p}<0.01)$. SFA correlated negatively, but not significantly, with HDL-C levels because of the significant C14:0 correlation with HDL-C levels $(-0.27, \mathrm{p}<0.01)$, while C16:0 and C18:0 did not correlate with HDL-C levels. NEFA that were correlated with HDL-C at univariate analysis were included in a multiple regression analysis (MRA) that also included the most abundant plasma NEFA, using age and gender as covariates. The MRA showed that only $\mathrm{C} 14: 0(\beta=-0.24 \mathrm{p}<0.01), \mathrm{C} 18: 1 \mathrm{n} 9(\beta=-0.22 \mathrm{p}<0.01)$ and C20:1n9 (cis-11-Eicosenoic, $\beta=-0.19 \mathrm{p}<0.01$ ) were independently and negatively correlated with HDL-C levels, while C16:1 was positively correlated $(\beta=+0.19 \mathrm{p}=0.03)$ at MRA but not at univariate analysis. Correlation coefficients were not significantly affected by measures of adiposity, as B.M.I. and waist circumference (Supplementary Tables S-1).

\subsection{Effects of FA conditioning on HDL catabolism in liver cultured cells (HepG2)}

The FA used to condition HepG2 cells were selected among those found correlated with HDL-C levels in the population study or 
resulted more abundant in the plasma with the exception of $\mathrm{C} 20: 1$, because of the presence of C18:1 as similar MUFA. FA were tested "in vitro" in a liver hepatoma HepG2 cells model. HDL binding to cell surface was evaluated after conditioning the cell with single FA. Fig. 1 shows the kinetics of the DIL-HDL binding to cells surface after conditioning the cells with different FA. Individual FA data, fitted curves according to the first-order Michaelis-Menten model and estimated kinetic parameters are presented in Supplementary Fig. S1-S5. A summary of kinetics estimates is shown in Table 3. The data show that no FA significantly increased HDL binding by increasing the amount of HDL bound to saturable sites of cell membrane (Bmax), while C14:0 showed a peculiar behavior, increasing the HDL surface binding by increasing the amount of HDL bound to non-saturable sites (slope of linear fitting, kasp $+43 \%, p<0.001$ ) on cell surface. All FA but C18:0 seemed to increase the affinity for cell surface binding sites (decrease of $\mathrm{kmm}$ constant).

\subsection{HSPG contribution to HDL catabolism in liver cultured cells (HepG2) after conditioning with FA}

In order to test the hypothesis that the HSPG moiety of hepatocytes surface might account for the peculiar kinetics of C14:0, DIL labeled HDL were competed with liver cells before and after treatment with heparinase I and III, an enzyme mixture able to hydrolyze cell surface HSPG. Fig. 2 shows that heparinases abolished about the $30 \%(\mathrm{p}=0.001)$ of total HDL binding in cells treated with C14:0, while no effect could be detected in other FA conditioned cells. All other FA reduced the loss of HDL binding after HSPG stripping shown in non-conditioned cells $(-14 \%, p=0.01)$, and C18:1n9 even increased (not significantly) HDL binding (per mg of cell protein) after HSPG cleavage $(+9 \%, \mathrm{p}=0.18)$.

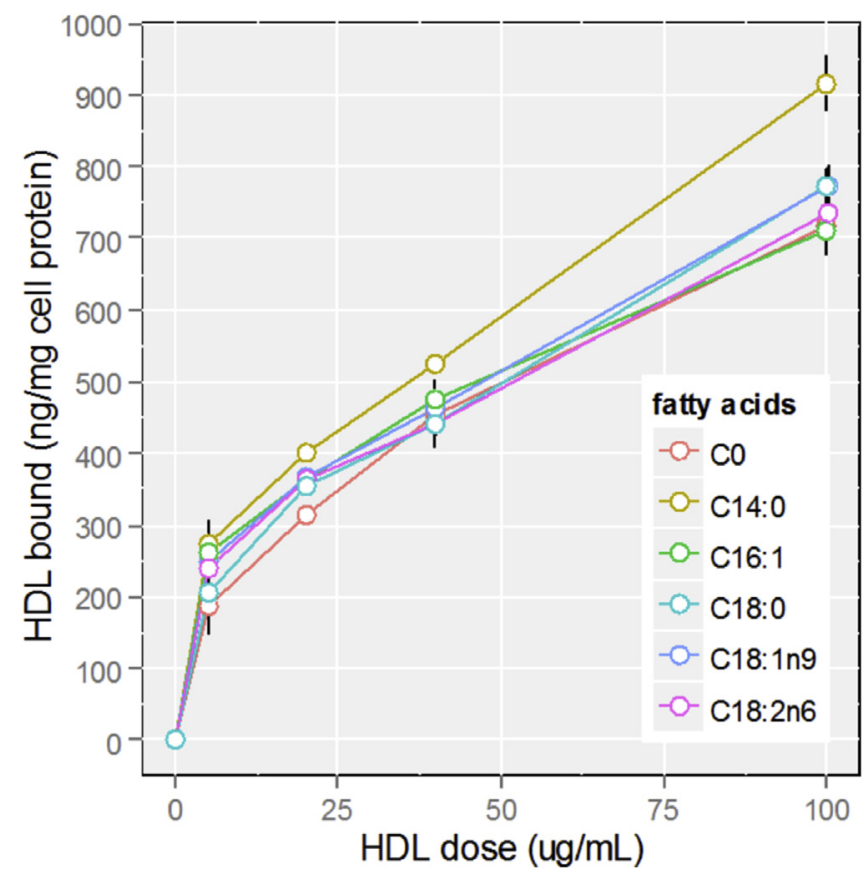

Fig. 1. DIL-HDL binding to HepG2 cells conditioned with FA. HDL binding curves were obtained after conditioning the cells with the FA shown in the legend (see methods). Error bars $=$ SD of triplicates. X axis = DIL HDL concentration in the cell medium. Yaxis = DIL HDL bound to HepG2 cell surface.

\subsection{Effects of FA conditioning on HDL-CE internalization in liver cultured cells (HepG2)}

Internalization of fluorescent $\mathrm{CE}$ was performed by incubating FA-conditioned cells with recombinant HDL containing BODIPYFL12. Internalized CE were measured by flow cell fluorocytometry. FA did not modify the CE internalization with the exception of C14:0 that significantly increased CE internalization by $32 \%$ $(\mathrm{p}=0.01)$ as shown in Table 3.

\subsection{Effects of FA conditioning on SR-B1 cell-surface expression on liver cultured cells (HepG2)}

The effect of FA on SR-B1 cell surface expression was evaluated by immuno-cytofluorimetry on FA conditioned HepG2 cells. No significant differences in SR-B1 expression were found. Still, SFA (C14:0, C18:0) showed a rough 20\% reduction of SR-B1 expression, while C18:1n9 showed a non significant $+12 \%$ increase (Table 3 , $\mathrm{p}=0.27$ ).

\section{Discussion}

In this paper we first investigated how plasma NEFA composition correlated with plasma HDL-C levels in a free living population of Southern Italy. This population is a typical Mediterranean population following a "modern" version of the Mediterranean diet with a lower content of fibers and an excess of introduced calories in comparison with the "traditional" diet [15]. Olive oil constitutes the majority of dietary fat. This population is characterized by a high prevalence of obesity $[15,16]$ and metabolic syndrome (MetS) [16] that also represents a relevant risk factor for CV events observed during a 15 years follow-up [16]. More, the average HDL-C levels of this population are slightly lower than the Italian levels $[15,16]$.

We found that HDL-C levels of this population correlated positively with the proportion of plasma PUFA and negatively with SFA. Among individual NEFA, HDL-C levels strongly and negatively correlated with $\mathrm{C} 14: 0, \mathrm{C} 18: 1 \mathrm{n} 9$ and $\mathrm{C} 20: 1 \mathrm{n} 9$, and positively with C16:1. Different studies showed that C14:0 positively correlated with plasma HDL-C levels, and a large meta-analysis including 60 dietary intervention studies concluded that the increase of HDL-C due to SFA progressively decreases with the elongation of the acyl chain, being maximal for C12:0 (lauric acid) and not relevant for C18:0 [2]. The dietary supplementation of C14:0 did not produce a significant raise in HDL-C levels in the same study [2]. Another large meta-analysis showed that the isocaloric replacement of C18:0 with C12:0/C14:0/C16:0 did not significantly raise the HDL-C levels [22]. These contrasting results might be explained by the heterogeneous characteristics of the studied populations. The population of the present study shows a high prevalence of MetS [16]. High levels of C14:0 were associated to the risk of MetS with an odds ratio of 5.84 in women and 2.23 in men in study of obese subjects [23]. It is possible that the inverse relationship between C14:0 and low HDL-C in obese subjects might be explained by the increase of MetS induced by C14:0, since low levels of HDL-C are characteristic of MetS patients [16].

Another explanation of these results might be related to the choice to assay NEFA instead of total FA in the present study. Dietary FA modify not only NEFA but also total FA composition, and the modification of esterified FA profile may result a better predictor of HDL levels than NEFA profile.

C18:1n9 was correlated with lower levels of HDL-C in our study, being oleic acid highly represented in the Mediterranean diet of this population [15], while C18:2n6 was associated with higher HDL-C levels, though the latter association was not maintained at 
Table 3

HDL-CE uptake and SR-B1 cell-surface expression in HepG2 Hepatoma cells conditioned with FA.

\begin{tabular}{|c|c|c|c|c|c|}
\hline \multirow[b]{2}{*}{ Fatty acids } & \multicolumn{3}{|c|}{ HDL binding kinetics parameters } & \multicolumn{2}{|l|}{ Cytofluorimetry } \\
\hline & $\mathrm{Bmax}^{\mathrm{a}}$ & $\mathrm{Kmm}^{\mathrm{b}}$ & $\operatorname{Kasp}^{c}$ & Fluorescent CE internalization $^{\mathrm{d}}$ & Cell surface SR-B1 expression ${ }^{e}$ \\
\hline $\mathrm{CO}$ & $100 \pm 42$ & $100 \pm 87$ & $100 \pm 29$ & $100 \pm 3$ & $100 \pm 13$ \\
\hline $\mathrm{C} 14: 0$ & $97 \pm 27(0.83)$ & $20 \pm 57(0.006)$ & $143 \pm 23(<0.001)$ & $132 \pm 8(0.01)$ & $82 \pm 20(0.27)$ \\
\hline C16:1 & $109 \pm 22(0.43)$ & $41 \pm 47(0.03)$ & $90 \pm 17(0.31)$ & $101 \pm 11(0.51)$ & $99 \pm 11(0.95)$ \\
\hline $\mathrm{C} 18: 0$ & $91 \pm 42(0.59)$ & $55 \pm 118(0.25)$ & $115 \pm 32(0.18)$ & $96 \pm 4(0.316)$ & $86 \pm 13(0.28)$ \\
\hline C18:1n9 & $96 \pm 19(0.79)$ & $31 \pm 44(0.01)$ & $112 \pm 16(0.171)$ & $97 \pm 7(0.67)$ & $112 \pm 10(0.26)$ \\
\hline $\mathrm{C} 18: 2 \mathrm{n} 6$ & $96 \pm 17(0.79)$ & $35 \pm 39(0.01)$ & $103 \pm 13(0.70)$ & $96 \pm 4(0.66)$ & $101 \pm 10(0.87)$ \\
\hline
\end{tabular}

Data are expressed as percent of non-conditioned cells $\pm \mathrm{SD}$, Student's T test vs. non-conditioned cells, and p-value in brackets.

a $B m a x=$ amount of DIL-HDL bound to saturable cell surface sites.

b $\mathrm{kmm}=$ Michaelis Menten constant.

c Kasp = linear non specific binding constant (see methods).

d Cell internalization of BODIPY FL12 (cholesteryl ester fluorescent analog).

e SR-B1 cell surface expression evaluated by immuno-cytofluorimetry.

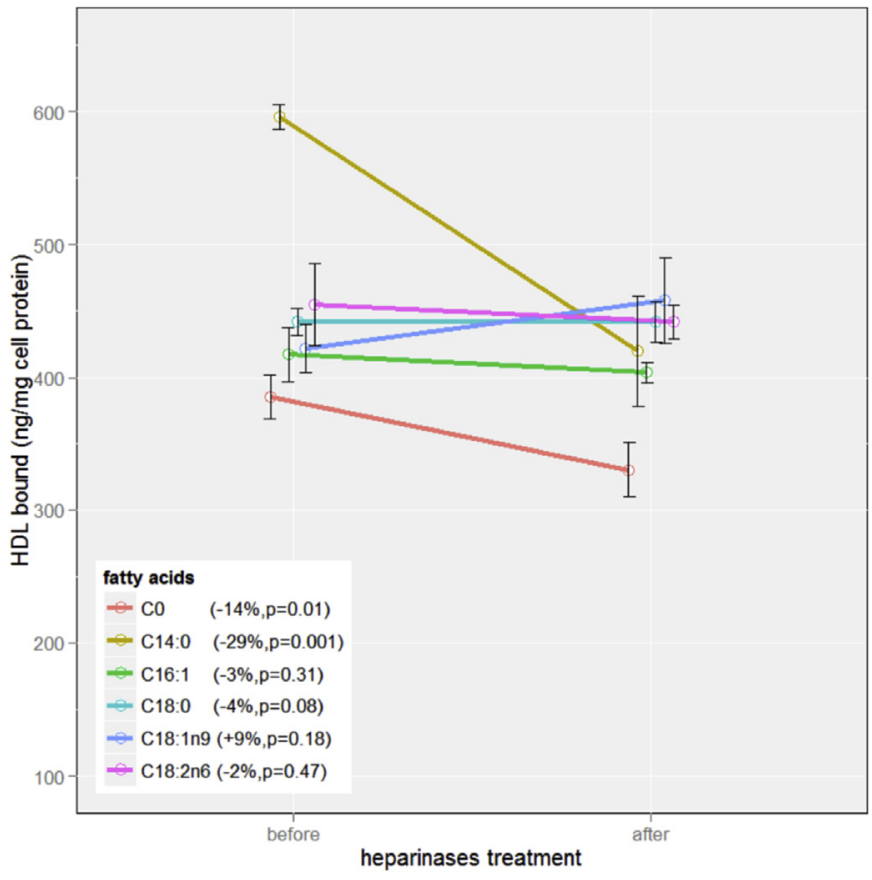

Fig. 2. DIL-HDL binding to HepG2 cells conditioned with FA after HSPG removal by heparinases treatment. HDL binding values were obtained after conditioning the cells with the FA shown in the legend (see methods). Error bars = SD of triplicates. X axis = "before" indicates HDL binding before heparinases treatment, "after" indicates HDL binding after the treatment. Y-axis $=$ DIL HDL bound to HepG2 cell surface $\times$ mg of cell proteins. The legend also shows the percent loss of binding after heparinases treatment and the relative Student's t test p-value, (before vs. after heparinases treatment)

multivariate analysis.

We tried to understand if an altered hepatic catabolism of HDL induced by FA might contribute to explain the results found in the population study. We used an "in vitro" model of cultured hepatoma cells conditioned with those FA that resulted correlated (as NEFA) with plasma HDL-C levels in the population study (Table 2), or that resulted very abundant in the plasma, as C18:0. We decided to exclude C20:1n9 to avoid over-representation of MUFA, being C18:1 about ten-times more abundant than $\mathrm{C} 20: 1$ and very similar to it in terms of chain length.

The main result of the "in vitro" part of the study consisted in the finding that myristic acid modified the HDL binding to liver cultured cells in a peculiar manner. C14:0 increased the nonspecific binding of HDL to cell surface and it did not affect the saturable receptor-mediated binding (Fig. 1, Table 2 and
Supplementary Figs. S-1). The increase of HDL binding caused by C14:0 cell conditioning showed a linear dose-response effect between $0.25 \mathrm{mM}$ and $1 \mathrm{mM}$ of supplemented C14:0 (data not shown). The increase of HDL binding is partly explained by the presence of HSPG, since their removal by heparinases treatment determined roughly a $30 \%$ loss of HDL binding activity in comparison with non-conditioned cells and all the other FA (Fig. 2). C14:0 conditioning also increased the internalization of fluorescent CE contained in synthetic HDL3 by $+32 \%$ (Table 3 ). HSPG are an essential part of the lipoproteins-CE removal from the bloodstream. HDLs are trapped by the PG matrix surrounding the hepatocytes and stripped of their CE content by the HL in exchange of triglycerides (TG) [7]. This mechanism could explain why CE internalization in the hepatic cells was increased by C14:0, though this result is not consistent with previous reports. In a dietary intervention study, a diet rich in C14:0 and other SFA was associated with a reduced activity of $\mathrm{HL}$, resulting in a positive correlation with LDL size [24]. Also, a diet supplementation with SFA in monkeys [5] determined an increase of plasma HDL-C and a decrease of $\mathrm{CE}$ hepatic content, suggesting that $\mathrm{CE}$ internalization was not increased but reduced in those models. The difference between the metabolism of the animal models and that of isolated cultured cells may explain this apparent discrepancy. Interestingly, high C14:0 levels were found associated with lower $\operatorname{Lipoprotein}(a)[\operatorname{Lp}(a)]$ plasma levels [25]. Since C14:0 is probably not able to affect apo(a) synthesis, being apo(a) levels under strict genetic control [25], it is plausible that C14:0 reduces $\mathrm{Lp}(\mathrm{a})$ levels by increasing $\mathrm{Lp}(\mathrm{a})$ trapping by HSPG, a relevant mechanism involved in $\mathrm{Lp}(\mathrm{a})$ catabolism [26]. Our results suggests that C14:0 increases the catabolism of HDL-CE, Lp(a), and probably VLDL by modifying the proteoglycan extracellular matrix. We also evaluated the effect of FA on SR-B1 protein expression on the liver cells surface. We measured the surface-exposed SR-B1 by immuno-cytofluorimetry and we found that C14:0 and C18:0 showed a trend toward the decrease in SR-B1 expression (roughly by $20 \%$ though not significant, Table 3 ). If confirmed and validated, this result would be in accord with another study showing reduced a SR-B1 expression in hamsters treated with C14:0 [27]. Dietary interventions enriched in C14:0 increased circulating HDL-3 particles [28,29], that are generated by SR-B1 from nascent HDL [7], but the increase of HDL3 in these studies has been explained by the impairment of the HDL3>HDL2 conversion due to the lecithin-cholesterol acyl transferase (LCAT) inhibition induced by C14:0 [29].

All the results concerning the other investigated FA are less straightforward to interpreter. C18:1n9 was associated with lower HDL-C levels in the population study confirming large association studies $[2,3]$. The mechanism might be related to an increase of HDL clearing related to SR-B1. We observed a not significant $12 \%$ 
increase of SRB1 on the cell surface (Table 3), but this trend was supported by neither an increase in HDL particles bound to cell surface nor an increase in CE internalization under C18:1n9 cells conditioning. C18:1n9 is a powerful PPARs activator [12], so it is possible that the negative correlation with plasma HDL levels might be related to the effect of PPARs activation in liver cells, but it is not clear why C18:2n6, also a potent PPARs activator, did not show any relevant correlation with SR-B1 in this study.

The main limit of this study is that the "in-vitro" experiments were focused only on HDL particles catabolism by liver cells, and it is not always possible to find a straight correlation between the data obtained "in-vivo" from human studies and the limited catabolic aspects elucidated by the "in-vitro" experiments. In spite of this limitation, a novel mechanism by which C14:0 affects HDL-C catabolism is clearly demonstrated in cultured hepatoma cells.

In conclusion, we showed that myristic acid is negatively correlated with plasma levels of HDL-C in a Mediterranean population characterized by an excess of obesity and metabolic syndrome. We suggest that part of this correlation might be explained by an increase of HDL binding to hepatic HSPG and subsequent cholesteryl esters stripping by proteoglycans-bound lipases. Our study reinforces the necessity to reduce overweight and to decrease the amount of dietary saturated fats in order to improve population's health.

\section{Acknowledgments}

The authors declare no conflict of interests. The present paper did not use dedicate funds or grants.

\section{Appendix A. Supplementary data}

Supplementary data related to this article can be found at http:// dx.doi.org/10.1016/j.atherosclerosis.2015.12.036.

\section{References}

[1] G. Michas, R. Micha, A. Zampelas, Dietary fats and cardiovascular disease: putting together the pieces of a complicated puzzle, Atherosclerosis 234 (2) (2014) 320-328.

[2] R.P. Mensink, P.L. Zock, A.D. Kester, et al., Effects of dietary fatty acids and carbohydrates on the ratio of serum total to HDL cholesterol and on serum lipids and apolipoproteins: a meta-analysis of 60 controlled trials, Am. J. Clin. Nutr. 77 (2003) 1146e55.

[3] F.H. Mattson, S.M. Grundy, Comparison of effects of dietary saturated, monounsaturated, and polyunsaturated fatty acids on plasma lipids and lipoproteins in man, J. Lipid Res. 26 (2) (1985) 194-202.

[4] J.M. Ordovas, D. Corella, L.A. Cupples, S. Demissie, A. Kelleher, O. Coltell, P.W. Wilson, E.J. Schaefer, K. Tucker, Polyunsaturated fatty acids modulate the effects of the APOA1 G-A polymorphism on HDL-cholesterol concentrations in a sex-specific manner: the Framingham Study, Am. J. Clin. Nutr. 75 (1) (2002) 38-46.

[5] M.E. Brousseau, J.M. Ordovas, J. Osada, J. Fasulo, S.J. Robins, R.J. Nicolosi, E.J. Schaefer, Dietary monounsaturated and polyunsaturated fatty acids are comparable in their effects on hepatic apolipoprotein mRNA abundance and liver lipid concentrations when substituted for saturated fatty acids in cynomolgus monkeys, J. Nutr. 125 (3) (1995 Mar) 425-436.

[6] M.D. Giron, F.J. Mataix, M.D. Suarez, Long-term effects of dietary monounsaturated and polyunsaturated fatty acids on plasma lipids in dogs, Arch. Int. Physiol. Biochim. Biophys. 100 (5) (1992) 321-326.

[7] A. von Eckardstein, M. Hersberger, L. Rohrer, Current understanding of the metabolism and biological actions of HDL, Curr. Opin. Clin. Nutr. Metab. Care 8 (2) (2005) 147-152.

[8] Y. Uehara, S. Miura, A. von Eckardstein, S. Abe, A. Fujii, Y. Matsuo, S. Rust, S. Lorkowski, G. Assmann, T. Yamada, K. Saku, Unsaturated fatty acids suppress the expression of the ATP-binding cassette transporter G1 (ABCG1) and ABCA1 genes via an LXR/RXR responsive element, Atherosclerosis 191 (1) (2007) $11-21$.

[9] S.E. Michaud, G. Renier, Direct regulatory effect of fatty acids on macrophage lipoprotein lipase: potential role of PPARs, Diabetes 50 (3) (2001) 660-666.

[10] L. Lagrost, Regulation of cholesteryl ester transfer protein (CETP) activity: review of in vitro and in vivo studies, Biochim. Biophys. Acta 1215 (3) (1994 Dec 8) 209-236.

[11] G.J. Botma, D. van Deursen, D. Vieira, M. van Hoek, H. Jansen, A.J. Verhoeven, Sterol-regulatory-element binding protein inhibits upstream stimulatory factor-stimulated hepatic lipase gene expression, Atherosclerosis 179 (1) (2005) 61-67.

[12] H. Keller, C. Dreyer, J. Medin, A. Mahfoudi, K. Ozato, W. Wahli, Fatty acids and retinoids control lipid metabolism through activation of peroxisome proliferator-activated receptor-retinoid X receptor heterodimers, Proc. Natl. Acad. Sci. U. S. A. 90 (6) (1993) 2160-2164.

[13] L. Malerød, M. Sporstøl, L.K. Juvet, A. MoU.S.A.vi, T. Gjøen, T. Berg, Hepatic scavenger receptor class B, type I is stimulated by peroxisome proliferatoractivated receptor gamma and hepatocyte nuclear factor 4alpha, Biochem. Biophys. Res. Commun. 305 (3) (2003 Jun 6) 557-565.

[14] A. Sheril, S.M. Jeyakumar, T. Jayashree, N.V. Giridharan, A. Vajreswari, Impact of feeding polyunsaturated fatty acids on cholesterol metabolism of dyslipidemic obese rats of WNIN/GR-Ob strain, Atherosclerosis 204 (1) (2009 May) $136-140$.

[15] C.M. Barbagallo, G. Cavera, M. Sapienza, D. Noto, A.B. Cefalù, F. Polizzi, F. Onorato, G. Rini, G. Di Fede, M. Pagano, G. Montalto, M. Rizzo, G. Descovich, A. Notarbartolo, M.R. Averna, Nutritional characteristics of a rural Southern Italy population: the Ventimiglia di Sicilia Project, J. Am. Coll. Nutr. 21 (6) (2002 Dec) 523-529.

[16] D. Noto, C.M. Barbagallo, A.B. Cefalù, A. Falletta, M. Sapienza, G. Cavera, S. Amato, M. Pagano, M. Maggiore, A. Carroccio, A. Notarbartolo, M.R. Averna, The metabolic syndrome predicts cardiovascular events in subjects with normal fasting glucose: results of a 15 years follow-up in a Mediterranean population, Atherosclerosis 197 (1) (2008 Mar) 147-153. Epub 2007 Apr 26.

[17] G. Lepage, C.C. Roy, Specific methylation of plasma nonesterified fatty acids in a one-step reaction, J. Lipid Res. 29 (2) (1988 Feb) 227-235.

[18] D. Noto, M. Rizzo, C.M. Barbagallo, A.B. Cefalù, A.L. Verde, F. Fayer, A. Notarbartolo, M.R. Averna, Low-density lipoproteins generated during an oral fat load in mild hypertriglyceridemic and healthy subjects are smaller, denser, and have an increased low-density lipoprotein receptor binding affinity, Metabolism 55 (10) (2006 Oct) 1308-1316.

[19] A.B. Cefalù, D. Noto, L. Magnolo, E. Pinotti, M. Gomaraschi, S. Martini, G.B. Vigna, L. Calabresi, P. Tarugi, M.R. Averna, Novel mutations of CETP gene in Italian subjects with hyperalphalipoproteinemia, Atherosclerosis 204 (1) (2009 May) 202-207.

[20] H.R. Yao, J. Liu, D. Plumeri, Y.B. Cao, T. He, L. Lin, Y. Li, Y.Y. Jiang, J. Li, J. Shang, Lipotoxicity in HepG2 cells triggered by free fatty acids, Am. J. Transl. Res. 3 (3) (2011 May 15) 284-291.

[21] M.W. Huff, D.B. Miller, B.M. Wolfe, P.W. Connelly, C.G. Sawyez, Uptake of hypertriglyceridemic very low density lipoproteins and their remnants by HepG2 cells: the role of lipoprotein lipase, hepatic triglyceride lipase, and cell surface proteoglycans, J. Lipid Res. 38 (7) (1997) 1318-1333.

[22] J.E. Hunter, J. Zhang, P.M. Kris-Etherton, Cardiovascular disease risk of dietary stearic acid compared with trans, other saturated, and unsaturated fatty acids: a systematic review, Am. J. Clin. Nutr. 91 (1) (2010 Jan) 46-63, http:// dx.doi.org/10.3945/ajcn.2009.27661. Epub 2009 Nov 25.

[23] J. Mayneris-Perxachs, M. Guerendiain, A.I. Castellote, R. Estruch, M.I. Covas, M. Fitó, J. Salas-Salvadó, M.A. Martínez-González, F. Aros, R.M. Lamuela-Raventós, M.C. López-Sabater, for PREDIMED Study Investigators. Plasma fatty acid composition, estimated desaturase activities, and their relation with the metabolic syndrome in a population at high risk of cardiovascular disease Clin. Nutr. 33 (1) (2014 Feb) 90-97.

[24] D.M. Dreon, H.A. Fernstrom, H. Campos, P. Blanche, P.T. Williams, R.M. Krauss, Change in dietary saturated fat intake is correlated with change in mass of large low-density-lipoprotein particles in men, Am. J. Clin. Nutr. 67 (5) (1998 May) 828-836.

[25] T. Tholstrup, P. Marckmann, B. Vessby, B. Sandström, Effect of fats high in individual saturated fatty acids on plasma lipoprotein[a] levels in young healthy men, J. Lipid Res. 36 (7) (1995) 1447-1452.

[26] G. Camejo, E. Hurt-Camejo, O. Wiklund, G. Bondjers, Association of apo B lipoproteins with arterial proteoglycans: pathological significance and molecular basis, Atherosclerosis 139 (2) (1998) 205-222.

[27] C. Loison, F. Mendy, C. Sérougne, C. Lutton, Dietary myristic acid modifies the HDL-cholesterol concentration and liver scavenger receptor BI expression in the hamster, Br. J. Nutr. 87 (3) (2002 Mar) 199-210.

[28] T. Tholstrup, P. Marckmann, J. Jespersen, B. Sandström, Fat high in stearic acid favorably affects blood lipids and factor VII coagulant activity in comparison with fats high in palmitic acid or high in myristic and lauric acids, Am. J. Clin. Nutr. 59 (2) (1994 Feb) 371-377.

[29] A.M. Bérard, H. Dabadie, A. Palos-Pinto, M.F. Dumon, M. Darmon, Reduction of dietary saturated fatty acids correlates with increased plasma lecithin cholesterol acyltransferase activity in humans, Eur. J. Clin. Nutr. 58 (6) (2004 Jun) 881-887. 